\title{
Objetos de estudo da Comunicação Organizacional e das Relações Públicas: um quadro conceitual
}

\author{
Subject matters of Organizational Communication \\ and of Public Relations: a contextual outlook
}

\section{Objetos de estudio de la Comunicación Organizacional y de las Relaciones Públicas: un cuadro conceptual}

Ivone de Lourdes Oliveira

- Doutora em Comunicação e Cultura pela Universidade Federal do Rio de Janeiro (UFRJ)

- Mestre em Ciências da comunicação pela Escola de Comunicações e Artes da Universidade de São Paulo (ECA-USP)

- Diretora da Faculdade de Comunicação e Artes da PUC-Minas

- Professora do Curso de Mestrado em Comunicação Social Interações Midiáticas da PUC-Minas

- Coautora do livro 0 que é comunicação estratégica nas organizações? e coorganizadora do livro Interfaces e tendências da comunicação no contexto das organizações

- Vice-presidente da Associação Brasileira de Pesquisadores de Comunicação Organizacional e de Relações Públicas (Abrapcorp)

- ivone@pucminas.br 
Esse texto tem como objetivo instigar discussões sobre o campo da Comunicação no contexto das organizações e, ao mesmo tempo, estabelecer alguns parâmetros que ajudem a entender a tênue fronteira entre esse campo e a habilitação em Relações Públicas. Para melhor esclarecer o tema, não deixando de reconhecer sua complexidade, são incluídas reflexões sobre o objeto de cada uma das áreas - comunicação no contexto organizacional e Relações Públicas. Questões epistemológicas e a complexidade do mundo organizacional são também abordadas na reflexão.

PALAVRAS-CHAVE: COMUNICAÇÃO • CONTEXTO ORGANIZACIONAL • RELAÇÕES PÚBLICAS • OBJETO DE ESTUdO

Abstract

This text aims to instigate discussions about the field of Communication within the context of organizations and at the same time to establish some parameters that help us to understand the thin line between this field and Public Relations accreditation. To better clarify the theme, and recognizing its complexity, our approach includes reflections on both subject matters communication in the context of organizations and Public Relations. Epistemological questions and the complexity of the organizational world are also added to the reflection.

KEYWORDS: COMMUNICATION • ORGANIZATIONAL CONTEXT • PUBLIC RELATIONS • SUBJECT-MATTERS OF STUDY

Resumen

El objetivo es instigar discusiones sobre el campo de la Comunicación en el contexto de las organizaciones, y, al mismo tiempo, establecer algunos parámetros que ayuden a entender la tenue frontera entre este campo de estudios y la graduación en Relaciones Públicas. Para dejar el tema más claro, sin dejar de reconocer su complejidad, se incluyen reflexiones sobre el objeto de estudio de cada una de las áreas: comunicación en el contexto organizacional y Relaciones Públicas. También se abordan en esta reflexión algunas cuestiones epistemológicas y la complejidad del mundo organizacional.

PALABRAS CLAVE: COMUNICACIÓN • CONTEXTO ORGANIZACIONAL • RELACIONES PÚBLICAS • OBJETOS DE ESTUDIO 
A preocupação em entender o objeto de estudo da Comunicação Organi-zacional, a partir de sua conexão com o campo teórico da Comunicação e o lugar das Relações Públicas nesse contexto é o objetivo deste artigo. Essa indagação tem aparecido com frequência nos encontros acadêmicos e, muitas vezes, em salas de aula, o que nos leva a elaborar algumas questões sobre o assunto. A preocupação em trabalhar as articulações da Comunicação Organizacional com as questões epistemológicas do campo da Comunicação e com outros saberes é incipiente no Brasil, apesar das iniciativas de alguns programas de pós-graduação.

Não se objetiva com isso buscar unicidade conceitual e/ ou engessar conceitos. Ao contrário, a intenção é provocar discussões que possam vislumbrar outras direções e estimular a reflexão sobre a temática. Para isso, busca-se trabalhar o conceito de Comunicação Organizacional relacionando-o com as Relações Públicas e as questões epistemológicas do campo.

Todo campo de conhecimento que pretenda ser científico tem de ser independente para se constituir como tal, por meio da demarcação de seu espaço de atuação e do seu lugar na pesquisa. Assim é preciso provocar esta discussão e criar pontos basilares, que facilitem a compreensão da diferença e da interseção entre as áreas estudadas.

\section{Comunicação no contexto organizacional}

Os processos de comunicação no contexto das organizações precisam ser compreendidos como lugares de confluência e de atuação transversal, tendo como referência o olhar da Comunicação, ainda que se busquem em outros saberes, subsídios conceituais para entender sua complexidade. A raiz epistemológica desses estudos encontra-se na Comunicação e, por esse motivo, falamos em "comunicação no contexto das organizações", em vez de Comunicação Organizacional, como ela é normalmente nomeada na literatura brasileira. Reconhece-se também sua relação intrínseca com o empírico. Mattos (2008, p. 18) mostra essa perspectiva, quando argumenta que

a Comunicação Organizacional diz respeito tanto a um campo de estudos quanto a um conjunto de fenômenos empíricos, sendo o primeiro considerado subdisciplina ou subárea da Comunicação e o segundo, práticas de comunicação complexas e variadas desenvolvidas no âmbito das organizações, sejam elas públicas ou privadas ou ainda do terceiro setor.

Recorremos às reflexões de Vera R. França (2002) para reafirmar a natureza relacional da comunicação no contexto organizacional e discutir o processo de significação a partir do compartilhamento de sentidos. Para a autora, a comunicação se localiza na interseção de três dimensões: a interacional, que se dá 
na relação dos interlocutores do processo de comunicação; a simbólica, que se manifesta nas práticas discursivas e que possibilita a produção de sentidos; e o contexto social, cultural e econômico onde se dá a interação.

Nessa perspectiva, pode-se conceituar a comunicação no contexto das organizações ${ }^{1}$ como um processo relacional que parte de práticas individuais e/ou de grupos para alcançar uma estrutura coletiva de significados, os quais dizem respeito às organizações e aos atores sociais envolvidos no processo interativo. Vê-se, então, que a comunicação no contexto das organizações apresenta duas naturezas distintas, as quais se completam no ato interativo: uma teórica e outra prática.

A natureza teórica é o processo de interação ${ }^{2}$ em si, negociada entre grupos e organização para sua legitimidade pública. Nesse processo, tanto a organização quanto os grupos são considerados atores sociais que efetuam trocas simbólicas e práticas entre si, por meio de discursos e intervenções que vão construir sentidos para os objetivos e políticas organizacionais. Já a natureza prática é a materialização do processo em seus aspectos estratégicos, intencionais e diretivos, que se efetuam por meio de instrumentos/técnicas de Jornalismo, Relações Públicas, Propaganda, Publicidade e Marketing.

A partir do exposto, busca-se delimitar como objeto de estudo da Comunicação Organizacional os atos de interação, que acontecem no ambiente interno das organizações e na sua relação com o mundo externo. Esses atos são constituídos pelos fluxos informacionais, os quais têm o papel de transmitir e veicular informações de cunho institucional ou mercadológico de interesse dos atores, para materializar a relação constituída, e pelos fluxos relacionais, que representam oportunidades de compartilhamento e troca de expectativas e demandas dos atores (a organização é também um ator). Esses dois movimentos são sustentados por práticas profissionais e técnicas específicas.

A força da interação está na dimensão relacional, no investimento de cada ator na relação estabelecida. Isso evidencia a importância da política, porque um ato comunicativo é um espaço de negociação, um lugar de exposição e discussão de interesses divergentes e demandas diferentes, que utilizam a argumentação para buscar pontos comuns de entendimento. Assim, pode-se reconhecer que é na relação entre os atores - organização e interlocutores - que o ato comunicativo se constitui nas organizações, realçando as (inter)subjetividades, as mensagens e o contexto.

1 Organizações são concebidas como atores sociais de ampla abrangência, já que estabelecem relações com a sociedade na condução de seus objetivos. Nesse sentido, incorporam variáveis econômicas, políticas, sociológicas, culturais e linguísticas.

2 Segundo Braga (2001) interação significa "processos simbólicos e práticos que, organizando trocas entre seres humanos, viabilizam as diversas ações e objetivos que se vêem engajados." 


\section{Relações Públicas}

As Relações Públicas são entendidas como uma das habilitações - conjunto de conhecimentos, aptidão, capacidades e práticas específicas - que compõem o quadro da comunicação no contexto das organizações. No caso de Relações Públicas, sua aptidão é a de conhecer e criar oportunidades de relacionamento da organização com grupos específicos. Identifica-se aí sua processualidade, que é a construção de relacionamentos e a intensificação de outros, de acordo com as necessidades e demandas da organização Não se pode pensar em Relações Públicas isoladas das ações de Jornalismo, de Propaganda, de Publicidade e de Marketing, pois o convívio delas é que materializa os processos interacionais da organização.

Enquanto a Comunicação Organizacional pensa estrategicamente a interação da organização com a sociedade em seus vários níveis, as Relações Públicas têm espaços e funções específicas na globalidade desse processo. Diante disso, pode-se considerar como objeto de estudo das Relações Públicas a construção de relacionamentos.

A produção científica de autores como Margarida Kunsch (1997), Vera R. França (1997), James Grunig (2003), Ruller e Vercic (2003) respaldam esse posicionamento, tendo eles trabalhado, ao longo das últimas duas décadas, a ideia do relacionamento como a essência das Relações Públicas. Segundo Grunig (2003, p. 84) "as organizações são menos vulneráveis às crises e a questões emergentes quando estabelecem relacionamentos duradouros com aqueles grupos que poderiam ser afetados pelas decisões e pelos comportamentos da organização". Fábio França (2003) também destaca o relacionamento como uma das funções principais da área.

Como a Comunicação Organizacional, as Relações Públicas caracterizam-se também por duas instâncias: uma, que é a essência da atividade, se constitui de fundamentos teóricos do campo da Comunicação; a outra, a empírica, que se compõe de ações profissionais. Estas são desenvolvidas nas organizações, que se caracterizam como o locus da produção. Essa articulação pode parecer sobreposição com a Comunicação Organizacional, mas não é, já que ambas tratam do mesmo fenômeno comunicacional. Evidentemente as duas são complementares, pois os relacionamentos estão imbricados nos processos interacionais e refletem a articulação do corpus teórico do campo da Comunicação com as ações e técnicas de intervenção prática das Relações Públicas.

\section{Considerações finais}

Percebe-se que a relação existente entre a concepção teórica da comunicação no contexto das organizações e as Relações Públicas é fluida e difusa e, por esse motivo precisa ser mais pesquisada. No momento atual da produção aca- 
dêmica é fundamental a disposição dos pesquisadores em aprofundar tal discussão a enfrentar a tensão presente.

A dificuldade pode estar na falta de compreensão de qual é o objeto de estudo de cada uma das duas áreas, pois entender a essência teórica que sustenta a experiência que se realiza no mundo profissional é essencial para o avanço das reflexões. Desentranhar os objetos de estudo das duas é complicado, devido à interseção entre eles, mas é um problema de pesquisa fundamental que pode esclarecer muitos pontos e questões que pareçam nebulosas.

A comunicação no contexto das organizações é um campo fértil de produção teórica, e as Relações Públicas pertencem a esse campo, apesar de se concretizarem em suas especificidades técnicas e profissionais. Nessa perspectiva, reafirma-se a importância de ampliar as pesquisas e pensar o corpus teórico a partir das questões epistemológicas e teóricas do campo da Comunicação. As referências dos estudos de interface de Braga (2001) e do paradigma relacional de Vera R. França (2002) nos possibilitam construir, em um exercício teórico que parte da prática dos processos, os objetos de estudos da Comunicação Organizacional e das Relações Públicas.

Constituir o corpus teórico de uma área de conhecimento significa transitar entre a tensão do fechamento de teorias e a abertura e pluralidade das experiências vivenciadas no mundo das práticas profissionais. Por isso é importante marcar um lugar teórico, já que essa tensão configura a natureza complexa das duas áreas. Apostamos na articulação entre elas, reconhecendo que as Relações Públicas estão no campo da Comunicação e que utilizam técnicas e processos para promover os relacionamentos da organização com os interlocutores e a comunicação no contexto das organizações, como a configuração do olhar da Comunicação em um contexto específico. A indicação de que qualquer fenômeno comunicacional se dá na relação e se institui em relação com o outro vem confirmar a nossa insistência em dizer que pertencemos ao campo teórico e conceitual da Comunicação.

Consideramos que a partir do olhar comunicacional os processos organizacionais adquirem tratamento interativo e a concepção da comunicação no contexto das organizações se amplifica como terreno mais sedimentado e fundamentado. Essa concepção pode facilitar o entendimento das forças em disputas no contexto organizacional e a compreensão dos discursos como parte do espectro teórico-prático, que constrói sentidos para legitimação e visibilidade da organização.

\section{Referências}

BRAGA, José L. Os estudos de interface como espaço de construção do campo da comunicação. Contracampo, Rio de Janeiro, UFF - Programa de Pós-Graduação em Comunicação, v. 10/11, n. 2, p. 219-235, 2004. 
FRANÇA, Fábio. Subsídios para o estudo do conceito de relações públicas no Brasil. Comunicação \& Sociedade, São Bernardo do Campo, PósCom-Metodista, a, 24, n. 39, p. 127-154, 1. sem. 2003.

FRANÇA, Vera Regina Veiga. Reflexões sobre a comunicação: esse estranho objeto. Geraes - Revista da Comunicação Social, Belo Horizonte: Departamento de Comunicação Social. Fafich-UFMG, n. 48, p. 2-7, jul. 1997.

FRANÇA, Vera Regina Veiga. Paradigmas da comunicação: conhecer o quê? In: MOTTA, Luiz Gonzaga et al. (Org.). Estratégias e culturas da comunicação. Brasília: Editora UnB, 2002. p.13-29.

GRUNIG, James E. A função das relações públicas na administração e sua contribuição para a efetividade organizacional e societal. Comunicação \& Sociedade, São Bernardo do Campo, PósCom-Metodista, a, 24, n. 39, p. 67-92, 2003.

KUNSCH, Margarida M. Krohling. Relações públicas e modernidade: novos paradigmas na comunicação organizacional. São Paulo: Summus, 1997.

OLIVEIRA, Ivone de Lourdes; SOARES, Ana Thereza N. (Org.). Interfaces e tendências da comunicação no contexto das organizações. São Caetano do Sul, SP: Difusão, 2008.

OLIVEIRA, Ivone de Lourdes; PAULA, Maria Aparecida de. 0 que é comunicação estratégica nas organizações? São Paulo: Paulus, 2009.

VAN RULER, Betteke; VERCIC, Dejan. Perspectivas europeias das relações públicas. Comunicação \& Sociedade, São Bernardo do Campo, PósCom-Metodista, a. 24, n. 39, 155-174, 2003. 